\title{
Consumers' Attitude Toward Socially Responsible Consumerism in the Sustainable Fashion Market
}

\author{
Daniela Delieva ${ }^{1}$, Hyo Jin Eom² \\ ${ }^{1}$ M.S. Candidate, Department of Media and Communication, Sugkyunkwan University \\ ${ }^{2}$ Ph.D., University of Georgia, Institute of Social Research, Korea University, 145 Anam-ro, Anam-dong, Seongbuk-gu, \\ Seoul, 02841, South Korea \\ Correspondence: Hyo Jin Eom, Ph.D., University of Georgia, Institute of Social Research, Korea University, 145 \\ Anam-ro, Anam-dong, Seongbuk-gu, Seoul, 02841, South Korea.
}

Received: March 6, 2019

doi:10.11114/bms.v5i1.4173

\author{
Accepted: March 23, 2019 \\ Online Published: March 25, 2019 \\ URL: https://doi.org/10.11114/bms.v5i1.4173
}

\begin{abstract}
The fashion industry is one of the most toxic industries, which has led luxury brands to get involved in their efforts to build a more sustainable fashion future. Although the current fashion industry has put efforts into introducing ethical and sustainable consumption, customers have displayed contradictory attitudes toward green products in the luxury sector. Specifically, customers have generally shown an interest in environmentally friendly apparel while many customers are also shown to be reluctant in purchasing sustainable fashion clothing. This study was aimed at analyzing key variables in regards to attitude towards sustainable fashion advertising for luxury brands. The results showed three statistically significant regression coefficients: Interdependent-self, independent-self, and perceived personal relevancy. In light of the previous discussion, this study also sheds more light into the construal-level influence based on the notion of self-construals on attitude toward sustainable fashion advertisement. Therefore, the results of this study provides empirical evidence for luxury fashion brands seeking to influence and increase green purchase behavior and this gives more insight into the decision making for luxury brand advertisement strategy.
\end{abstract}

Keywords: sustainable fashion, green advertising, self-construal, perceived consumer effectiveness, perceived personal relevance

\section{Introduction}

The fashion industry is one of the most toxic industry which puts attention to the increased concerns for sustainable fashion consumption (Kang, Liu, \& Kim, 2013). The fashion industry has shown some significant efforts in building a more sustainable future as environmental and social matters are becoming a priority for an increasing number of companies (Han, Seo, \& Ko, 2017). With regard to this phenominon, the terms 'ethical' and 'sustainable' clothing are often used interchangeably in the literature, amongst other terms such as 'eco' and'green' (Cervellon \& Wernerfelt, 2012; Lundblad \& Davies, 2016). Similary, sustainability can have several definitions, but most of the times is connected to companies having social and environmental responibility (Aguilera, Rupp, Williams, \& Ganapathi, 2007), informed purchasing decisions of eco-friendly and fair-trade products, and green orientation at companies (Bansal \& Roth, 2000; Chan, 2001; Joy, Sherry, Venkatesh, Wang, \& Chan, 2012). It is also often described as "fashion with a conscious" as it concerns labor conditions and the environment. Companies often consider the following major dimensions of sustainable fashion, choosing environmentally sustainable products, and employing sourcing and production methods compliant with the regulation of fair trade (Joergens, 2006). In this study, we use the term sustainablity for ethical and sustainable fashion, which is most widely used in literature on environment-friendly fashion.

Sustainable fashion is facing numerous challenges in terms of product development and the inclusion of new technologies into products (Goworek, Fisher, Cooper, Woodward, \& Hiller, 2012), which puts into a perspective of the importance of research on such challenges in the industry. Sustainability in the fashion industry is connected to the use of sustainable raw materials such as organic cotton, hemp, bamboo as well as recycled materials (Shen, Wang, Lo, \& Shum, 2012; Todeschini, Cortimiglia, Callegaro-de-Menezes, \& Ghezzi, 2017). The adoption of sustainable materials is a complex process because it involves the cost of sourcing sustainable materials and recycling is also one of the key 
measures that ensure sustainability in the fashion industry (Todeschini, Cortimiglia, Callegaro-de-Menezes, \& Ghezzi, 2017). Further, Todeschini et al. (2017) note that adopting recycling in the business model translates into implementing transformations to the cost structure, key activities, and partnerships, as fashion companies purchase recycled materials instead of processing them themselves.

With regard to such sustainablitity issues in the fashion industry, fashion brands have taken considerable attentions in reducing negative environmental effects, identifying characteristics of consumers with a strong environmental concern or the intention to behave in an environmentally friendly way (Lin, 2009; Lindenberg \& Steg, 2007; Vermeir \& Verbeke, 2006). A large body of research demonstrates a gap between such concerns and actual consumption behaviors (Han, Seo, \& Ko, 2017), showing that consumers have been reluctant in purchasing sustainable fashion items (Bray, Johns, \& Kilburn, 2010; Joergens, 2006) and they are less likely to purchase a luxury fashion product based on ethics alone (Davies, Lee, \& Ahonkhai, 2012). Further, they have been shown to be skeptical towards green advertisement in general (Sheehan \& Atkinson, 2012; Matthes \& Wonneberger, 2014). With regard to this matter, previous studies have provided mixed findings about consumers' responses for the ethical and sustainable luxury market (Davies, Lee, \& Ahonkhai, 2012; Kapferer, 2010; Steinhart, Ayalon, \& Puterman, 2013). Contrary to the green skepticism in advertisement in general, luxury advertisements tend to convey image dependent messages, which consumers interpret with their cultural symbols or values (Amatulli, Pino, Iodice, \& Cascio, 2016; Freire 2014), green advertising of luxury brands may increase consumers' positive attitude toward eco-friendly products depending on their individual characteristics. Moreover, since luxury brands convey social meanings to enhance consumers' self-perception, social identity, or social status, consumers' social comparisons (Bian \& Forsythe, 2012; Eom, Seock, \& Hunt-Hurst, 2019), green appeals of luxury advertisements may have different psychological mechanism underlying that influences ethical and sustainable consumption in the luxury brand markets. These studies suggested that it is important to identify factors that help to promote socially responsible consumption of luxury fashion brands.

Given that sustainability in the fashion industry is gaining momentum in various social movements, it is important to put light on the ways the consumer reflects and understands sustainable fashion marketing. Thus, this paper focuses mainly on individuals' self-perceptions and ecological perceptions to investigate their attitudes toward sustainable luxury fashion marketing and advertising. Specifically, this study investigates self-construals, perceived consumer effectiveness, and perceived personal relevance as predictors of attitude towards sustainable luxury fashion advertising.

\section{Conceptual Framework}

\subsection{Construal Level Theory and Self-Construals}

Construal level theory has received a great deal of attention within the customer-psychology domain by emphasizing that that high- and low-level construals differ in interpreting relevant mental representation (Liberman \& Trope, 1998; Trope \& Liberman, 2010; Trope, Liberman, \& Wakslak, 2007). Self-construal refers to the way in which a person thinks about and defines the self and hgh- level construals tend to be associated with primary, abstract, and decontextualized while low-level construals tend to depend on secondary, concrete, and contextualized (Liberman \& Trope, 1998; Trope \& Liberman, 2010). Construal level theory posits that psychological distance (the subjective perception of the distance between a person and an event) affects a person's mental construal of the event, leading to different information preferences and decision making. Psychological distance includes various dimensions such as temporal (distant future vs. near future), social (related to other people vs. related to oneself), spatial (remote vs. close location), and hypothetical (uncertain vs. certain) distance (Trope, Liberman, \& Wakslak, 2007; Trope \& Liberman, 2010). The self-construals are not only a way of viewing oneself but also a way of understanding one's relationship to the larger social world. Therefore, we can assume that self-construals and sustainable fashion consumption can have a connection; the self has the perception that is reflected in their environment concern. In this article, we intend to look at how self-construals influence consumer's decision making and attitude when it comes to advertising of sustainable fashion.

As the issue of sustainable advertising is becoming more and more fast-growing, the construal-level theory has used widely in academia as a theoretical concept for analyzing 'green' advertising or attitudes toward 'green' products (Arnocky, Stroink, \& DeCicco, 2007; Chang, Zhang, \& Xie, 2015; White \& Simpson, 2013). Previous research on green advertising, has used some of the multiple dimensions of the theory as a way to analyze and predict consumer attitude. Researchers have concluded that temporal distance messages (near vs. distant future) of green advertising can moderate the persuasiveness of the eco-friendly message (Chang, Zhang, \& Xie, 2015). Arnocky, Stroink, and DeCicco (2007) have found that the different dimensions of the self-construals can serve as a predictor for environmental concern.

\subsection{Interdependent Self-Construal and Independent Self-Construal}

According to Markus and Kitayama (1991), there are two construals to the self, independent self and interdependent self. The independent entails the notion that an individual sees himself or herself independently and individually, while the 
interdependent self entails a version of the self which is a part of a larger social relationship. The notion of independent and interdependent self-construals comes close to meaning with social identity theory, which indicates that the way people perceive themselves as individuals or group members can affect the goal and strategies of their consumption (Oyserman, 2013). The view of the self derives from a belief in the wholeness and uniqueness of each person's internal attributes. It gives rise to processes like "self-actualization," "realizing oneself," "expressing one's unique configuration of needs, rights, and capacities," or "developing one's distinct potential." The importance of the interdependent and independent construals comes from its potential moderating effect on consumer attitude toward socially oriented behavior. For example, under the influence of social norms (in the interdependent self-construal), people tend to make more ethical consumer decisions (Szmigin, Carrigan, \& McEachern, 2009).

Interdependent self-construal is defined as a self that emphasized public features such as status and roles in society, as well as belonging to community and being indirect in communication (Singelis, 1994). In non-Western cultures, the normative is the interdependent self-construal (Markus \& Kitayama, 1991; Singelis, 1994). Interdependence entails that the individual sees himself as part of a social relationship and his/her behavior is determined and organized by what one perceives to be the thoughts, feelings, and actions of others in the relationship. Within such a construal, the self becomes most meaningful when it's part of a social relationship. The interdependent self is found to be socio-centric, relational and connected. Singelis (1994) states that a person with emphasized interdependent self-construal consists of: (a) external features such as status, role and relationships, (b) belonging in a group, (c) filling one's social role and engaging in appropriate action, (d) being indirect in communication with others.

In contrast to interdependent self, the independent self reflects a concept about the self as an independent person, autonomous and self-contained (Markus \& Kitayama, 1991; Singelis, 1994). Independent self-construal is defined as a self that puts emphasis on internal abilities and feelings, promoting one's goals and expressing the self, as well as being direct in communication (Singelis, 1994). Markus and Kitayama (1991) discuss that the independent self is relatively more common in Western cultures than non-Western cultures. However, they also contend that within any given culture individuals will vary. The independent self is responsive to the social environment but it derives from the need to express internal attributes of the self. In conclusion, the independent self-construal is comprised of the following: 1) personal and internal thoughts and feelings, 2) expressing oneself and being unique, 3) being individualistic, and 4) being direct in communication. According to Singelis (1994) when thinking about themselves, people with highly developed independent self-construals will refer to their characteristics or ambitions rather than the feelings of behaviors of others.

\subsection{Perceived Consumer Effectiveness and Perceived Personal Relevance}

Perceived consumer effectiveness is defined as the extent to which they believe their purchase decisions and actions can contribute to solving environmental problems (Kang, Liu, \& Kim, 2013). As mentioned previously, environmental concern alone does not always bring out equivalent behavior, such as purchasing a sustainable product (Vermeir \& Verbeke, 2006). Previous studies have reported a serious discrepancy between concern for the environment and actual purchasing behavior in the textile and apparel consumption (Butler \& Francis, 1997; Domina \& Koch, 1998; Kim \& Damhorst, 1998; Ritch \& Schröder, 2012). Perceived consumer effectiveness (PCE) was found to be one of the most important factors when it comes to explaining environmentally conscious consumer behavior (Kim \& Choi, 2005; Webb, Mohr, \& Kim, 2012). Perceived consumer effectiveness is a measure of the individual's judgment in the ability of individual consumers to affect environmental resource problems (Roberts, 1996). Kim and Choi (2005) have found that perceived consumer effectiveness directly affects energy-saving and recycling behavior. Webb et al. (2008) also found perceived consumer effectiveness to be a significant variable when it comes to socially responsible behavior.

Perceived personal relevance (PPR) refers to an individual's beliefs that a certain object or behavior is associated with his/her personal lifestyle, value and self-image (Celsi, Chow, Olson, \& Walker, 1992). Perceived personal relevance or perceived personal involvement with an issue has been proven in numerous marketing and advertising researches to be a variable of utmost importance. Perceived personal relevance or personal involvement refers to an individual's beliefs that certain objects of behaviors associated with his personal lifestyle, values or self-image (Celsi, Chow, Olson, \& Walker, 1992). When consumers consider a certain issue to be more relevant to them, they tend to be more involved with the issue (Zaickowsky, 1985). Previous research has found that consumers of organic apparel have strongly identified themselves as socially responsible or environmental conscious (Husvedt \& Dickson, 2009).

\subsection{Attitude toward Green Advertisement}

As concern for the environment is rising, so is the interest and development of advertisement that suits eco-friendliness and environmental concern. Initial research in green advertising dealt with the descriptive analysis of environmental claims made in green advertisements. Green advertisement can be defined as any ad that meets the following conditions (Banerjee, Gulas, \& Iyer, 1995): 
1. Explicitly or implicitly addresses the relationship between a product/service and the bio-physical environment.

2. Promotes a green lifestyle with or without highlighting a product/service.

3. Presents a corporate image of environmental responsibility.

Banejree, Gulas, and Iyer (1995) found that the structure of green advertising can be seen in three dimensions; sponsor type (for-profit or nonprofit, ad focus whether the ad focuses on the advertiser or the consumer), and depth of ad (shallow, moderate, or deep depending on the extent of environmental information mentioned). In their research, the majority of advertisers promoted a green corporate image rather than focus on the environmental benefits of their product or service. Other studies suggest that classifications, environmental claims in advertising can be considered either substantive or associative (Carlson, Grove, \& Kangun, 1993). Substantive claims can be defined as significant benefits that are advertised by a company in order to promote and maintain the customers' perception of an organization as sustainable or environmentally responsible.

Consumers, however, have been noted as usually skeptical toward green advertisement claims by a large number of studies (Sheehan \& Atkinson, 2012; Bickart \& Ruth, 2012). Even green consumers are not always convinced by green advertisement. One of the main arguments of existing research is that consumers tend to distrust greed advertising because of the misleading claims made in them, which can be defined as greenwash (Matthes \& Wonneberger, 2014). Greenwash is a term describing an advertising practice of companies that claim environmental functionality or sustainability of their products without particular evidence and clear information (Parguel, Benoit-Moreau, \& Larceneux, 2011). Greenwash has been shown to cause customers to distrust the advertisement and eventually not purchase green products and be suspicious about them (Polonsky, Grau, \& Garma, 2010).

Based on the literature review presented so far, Figure 1 shows the theoretical framework of this study and the following hypotheses are formed:

H1: Interdependent self-construal will have a relationship with attitude toward green advertisement.

H2: Independent self-construal will have a relationship with attitude toward green advertisement.

H3: Perceived consumer effectiveness will significantly affect attitude toward green advertisement.

H4: Perceived personal relevancy will significantly affect attitude toward green advertisement.

H5: County will be associated with attitude toward green advertisement.

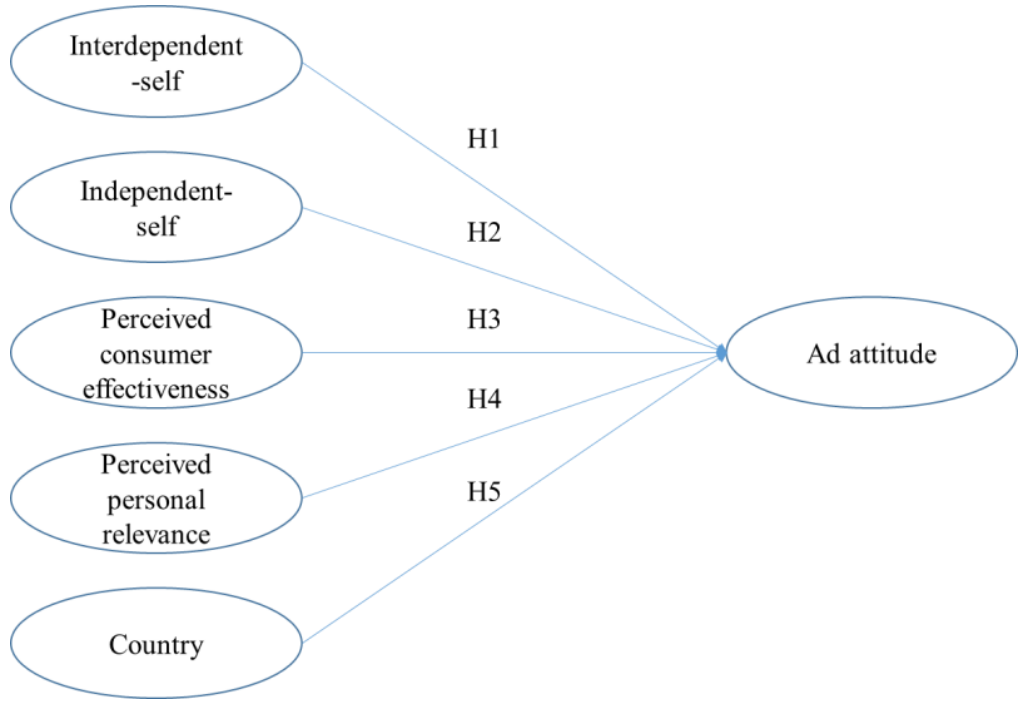

Figure 1. The proposed conceptual model for customer recommendation intention.

\section{Methodology}

\subsection{Data and Measurements}

A self-reported online survey with a convenient sampling method was administered for recruiting participants in both countries, Singapore and South Korea. A total of 104 responses $\left(M_{\text {age }}=27.8\right.$ years $)$ were collected from Asian consumers (Singapore: $n=48$, South Korea: $n=56$ ). Participants were given a fictional advertising of a luxury brand with a script to inform potential consumers about new plan of the brand. The script on the ad stated that the luxury brand has initiated to accept unwanted clothes and recycle the materials to increase sustainability. To measure the 
variables, measurements were slightly modified to our study context. The interdependent self-construal items were measured by adapting a scale from Singelis' (1994) study. We used the five items from the interdependent self-construal $(\alpha=.71)$, where respondents indicated their agreement with statements from the scale on a 7-point Likert scale $(1=$ strongly disagree, $7=$ strongly agree). For the independent self-construal, three items $(\alpha=.64)$ were adapted from Singelis' (1994) study and assessed the same way with interdependent self-construal items. Perceived consumer effectiveness was measured by adapting four items from Robert's (1996) study. To assess perceived consumer effectiveness, participants were asked to indicate their level of agreement with statements about their attitude and beliefs toward environmentally friendly purchase decisions on a 7-point Likert scale $(1=$ strongly disagree, $7=$ strongly agree). Four items were used for the measurements of perceived consumer effectiveness $(\alpha=.79)$. Perceived personal relevance was measured by adapting four items from Celsi et al.'s (1992) study $(\alpha=.89)$ by asking participants to indicate their level of agreement with statements about their ad attitude using four 7-point Likert type items $(\alpha=.96$; "reliable", "accurate", "truthful", "factual”; 1 = strongly disagree, 7 = strongly agree; Soh, Reid, \& King, 2009).

\section{Results and Discussion}

To analyze data, SPSS 22 Program was used for testing the hypothesized relationships in Figure 1. A multiple regression analysis was performed to evaluate how well attitude toward green ad was predicted by a set of other predictor variables (i.e.., interdependent-self, independent-self, perceived consumer effectiveness, perceived personal relevancy, country).

Table 1. Correlation Matrix of All Variables $(n=104)$

\begin{tabular}{lllllll}
\hline & 1 & 2 & 3 & 4 & 5 & 6 \\
\hline 1. Interdependent-self & 1.00 & & & & & \\
2. Independent-self & .04 & 1.00 & & & & \\
3. PEC & .09 & .26 & 1.00 & & & \\
4. PPR & .07 & .19 & .61 & 1.00 & & \\
5. Country & -.32 & -.08 & -.08 & .05 & 1.00 & \\
6. Ad attitude & .19 & -.23 & .13 & .26 & .08 & 1.00 \\
Mean & 4.94 & 4.66 & 5.24 & 4.49 & 0.54 & 4.68 \\
Standard Deviation & 0.88 & 1.16 & 0.95 & 1.27 & 0.50 & 1.19 \\
\hline
\end{tabular}

Note. PEC $=$ Perceived consumer effectiveness; PPR $=$ Perceived personal relevancy; Country $=$ Singapore 0 , South Korea 1.

The intercorrelations of all variables are reported in Table 1. There were six predictors including the country for which dummy coding was used (country $=$ Singapore 0 , South Korea 1). The regression equation for the hypothesized relationships is:

$$
\mathrm{Y}=3.122+0.303 \mathrm{X} 1-0.341 \mathrm{X} 2+0.078 \mathrm{X} 3+0.224 \mathrm{X} 4+0.292 \mathrm{X} 5
$$

where $\mathrm{Y}$ is the mean of attitude toward green ad, $\mathrm{X} 1$ is the mean of interdependent-self, $\mathrm{X} 2$ is the mean of independent-self, $\mathrm{X} 3$ is the mean of perceived consumer effectiveness, $\mathrm{X} 4$ is the mean of perceived personal relevancy, $\mathrm{X} 5$ is the type of the country.

The linear combination of the predictor variables was significantly related to attitude toward green ad showing $R^{2}$ $=.219, F(5,95)=5.321, p<.001$. There were three predictors that show statistically significant regression coefficients: $b=0.303(\beta=.225), p<.05$ for interdependent-self (H1: Supported), $b=-0.341(\beta=-.330), p=.001$ for independent-self (H2: Supported), and $b=0.244$ ( $\beta=.263), p<.05$ for perceived personal relevancy (H4: Supported). The regression coefficients of the two predictors, interdependent-self and perceived consumer relevancy, show positive values, indicating the unit increase of the respective variable would increase the predicted attitude toward green ad value to the amount of the regression coefficient conditioned upon other predictors are included and didn't change within the model. Note that the significant levels ( $p$ values) are based on the $t$-test results (not reported in detail here). Two other predictors, perceived consumer effectiveness and country, were not statistically significant (H3 and H5: Not supported).

As widely acknowledged, it is important for fashion brands to seek new ways to differentiate their products in the environmental era. Previous studies have suggested that green advertising may increase consumers' positive attitude toward eco-friendly products as well as achieve the product differentiation (Chen \& Chang, 2013). Although fashion brands have taken environmental friendly efforts into account, consumers have been shown to be skeptical towards 
green advertisement (Sheehan \& Atkinson, 2012; Matthes \& Wonneberger, 2014). Most importantly, there are mixed findings in regards to attitudes toward the ethical and sustainable luxury market (Davies, Lee, \& Ahonkhai, 2012; Kapferer, 2010; Steinhart, Ayalon, \& Puterman, 2013). Some scholars suggested that environmental claims may positively enhance consumer perceptions of luxury products (Steinhart, Ayalon, \& Puterman, 2013) while others suggested that consumers consider sustainability and ethics much less in luxury purchases, even though generally luxury products are considered more sustainable in comparison to ordinary products (Davies, Lee, \& Ahonkhai, 2012).

While previous research has largely suggested that ethical luxury have numerous barriers to be able to keep up with the current demand for ethical fashion, such as high prices and less active pursuit of information by ethical consumers (Davies, Lee, \& Ahonkhai, 2012), our results suggest that consumers' attitude toward luxury brand advertisements may depend their individual differences. The results of our study suggest that interdependent-self, independent-self, and perceived personal relevancy are associated attitude toward green advertisement for luxury brands. Further, the results showed that the interdependent self-construal has a positive and significant relationship with their attitude toward the green advertisement while the independent self-construal has a negative and significant relationship with their attitude toward the green advertisement. Previous research suggests that the independent and inter-dependent self-construal can serve as a predictor for environmental concern and cooperation (Arnocky, Stroink, \& DeCicco, 2007). This is in line with previous studies by supporting that consumers in the interdependent self-construal spectrum are more likely to have a positive attitude toward luxury fashion 'green' advertising. In light of the previous discussion, this study also sheds more light into the construal-level influence on attitude toward sustainable fashion advertisement. Therefore, the results of this study provides empirical evidence for luxury fashion brands seeking to influence and increase green purchase behavior.

\section{Implication and Future Research}

This study may have several academic and practical contributions. First, this study provides information on attitudes toward green advertisements for ethical and sustainable luxury market. Since green advertising has considered an effective way to position new fashion products for the green consumer markets, this study focused on consumers' individual differences to investigate the consumers' attitude toward green advertisement for the sustainable fashion markets. It is important to put light onto the ways the consumer reflects and understands sustainable luxury fashion marketing.

This leads to the second academic implication of this study, which suggests another important implication that the current study on sustainable fashion provides information on the connection between independent and inter-dependent self-construals and attitude toward sustainable fashion advertising. The psychological point of view in regards to luxury fashion states that consumers display purchase intention toward luxury brand products based on their personal perceptions, social comparisons, and social identities (Bian \& Forsythe, 2012; Eom, Seock, \& Hunt-Hurst, 2019). Attention to such psychological antecedents in regards to ethical fashion consumption has been limited in academia, therefore the current study can provide information on the connection between self-construals and attitude toward green advertising. Our research suggests that the interdependent self-construal as predictor toward advertisement attitude showed positive values.

Lastly, as mentioned previously luxury markets have not been studied extensively in the contexts of sustainability and green ethics. Previous research stated that consumers are generally skeptical towards 'green' advertisements (Matthes \& Wonneberger, 2014). Since ethical and sustainable luxury may play a role in sustainable fashion consumption, this study ascertains the importance of eco-friendly production and CSR activity by providing better understanding of consumers' perceptions and attitudes toward luxury brands in the sustainable market. This will enable luxury brand marketers to design the most appropriate and effective sustainable development strategies based on the situation and customers' needs.

The current research has several limitations in the nature of the sample used. This study has focused on the South Korean and Singaporean consumers, mainly college students. In addition to that, focusing on younger consumers might serve as another limitation as well, because young consumers have been shown to make purchase decisions differently than older ones. Young fashion consumers, for example, are more susceptible to emotional appeals (Joergens, 2006). This might serve as basis for future research that seeks to explore a wider sample size and groups. Additionally, young consumers might not have been exposed to sustainable luxury or sustainability in the past, and might not have had background knowledge about ethical consumerism. Future research might benefit from exploring more about the importance of knowledge and educational messages in sustainable or green advertising. Another limitation is that this study provides cross-sectional data, therefore this study can't observe the dynamics between self-construals and purchase behavior/intention through more longitudinal data. Further research might look at how variables such as perceived consumer effectiveness, perceived personal relevance and the self-consturals used in this study behave in a 
longitudinal study. Third limitation of this paper is that we focus on attitude, while for more precise and reliable results further research is needed on behavior based on green advertising. Therefore, future research might take into account researching the promotion of sustainable behavior and purchase decision making.

\section{References}

Aguilera, R. V., Rupp, D. E., Williams, C. A., \& Ganapathi, J. (2007). Putting the S back in corporate social responsibility: A multilevel theory of social change in organizations. Academy of Management Review, 32, 836-863. https://doi.org/10.5465/amr.2007.25275678

Amatulli, C., Pino, G., Iodice, M., \& Cascio, R. (2016). Linguistic and symbolic elements in luxury fashion advertising: A qualitative analysis. International Journal of Business and Management, 11, 265-271. https://doi.org/10.5539/ijbm.v11n9p265

Arnocky, S., Stroink, M., \& DeCicco, T. (2007). Self-construal predicts environmental concern, cooperation, and conservation. Journal of Environmental Psychology, 27, 255-264. https://doi.org/10.1016/j.jenvp.2007.06.005

Banerjee, S., Gulas, C., S., \& Iyer, E. (1995). Shades of Green: A multidimensional analysis of environmental advertising. Journal of Advertising, 24, 21-31. https://doi.org/10.1080/00913367.1995.10673473

Bansal, P., \& Roth, K. (2000). Why companies go green: A model of ecological responsiveness. Academy of Management Journal, 43, 717-36.

Bian, Q., \& Forsythe, S. (2012). Purchase intention for luxury brands: A cross cultural comparison. Journal of Business Research, 65, 1443-1451. https://doi.org/10.1016/j.jbusres.2011.10.010

Bickart, B. A., \& Ruth, A. J. (2012). Green eco-seals and advertising persuasion. Journal of Advertising, 41, 51-67. https://doi.org/10.1080/00913367.2012.10672457

Bray, J., Johns, N., \& Kilburn, D. (2010). An exploratory study into thefactors impeding ethical consumption. Journal of Business Ethics, 98, 597-608. https://doi.org/10.1007/s10551-010-0640-9

Butler, S. M., \& Francis, S. (1997). The effects of environmental attitudes on apparel purchasing behavior. Clothing and Textiles Research Journal, 15, 76-85. https://doi.org/10.1177/0887302X9701500202

Carlson, L., Grove, S. J., \& Kangun, N. (1993). A content analysis of environmental advertising claims: A matrix method approach. Journal of Advertising, 22, 27-39. https://doi.org/10.1080/00913367.1993.10673409

Celsi, R. L., Chow, S., Olson, J. C., \& Walker, B. A. (1992). The construct validity of intrinsic sources of personal relevance: an intraindividual source of felt involvement. Journal of Business Research, 25, 165-185. https://doi.org/10.1016/0148-2963(92)90015-4

Cervellon, M. C., \& Wernerfelt, A. S. (2012). Knowledge sharing among green fashion communities online: Lessons for the sustainable supply chain. Journal of Fashion Marketing and Management, 16, 176-192.

https://doi.org/10.1108/13612021211222860

Chan, R. Y. K. (2001). Determinants of Chinese consumers' green purchase behavior. Psychology \& Marketing, 18, 389-413. https://doi.org/10.1002/mar.1013

Chang, H., Zhang, L., \& Xie, G. X. (2015). Message framing in green advertising: the effect of construal level and consumer environmental concern. International Journal of Advertising, 34, 158-176. https://doi.org/10.1080/02650487.2014.994731

Chen, Y., \& Chang, C. (2013). Greenwash and green trust: The mediation effects of green consumer confusion and green perceived risk. Journal of Business Ethics, 114, 489-500. https://doi.org/10.1007/s10551-012-1360-0

Davies, I. A., Lee, Z., \& Ahonkhai, I. (2012). Do consumers care about ethical luxury?. Journal of Business Ethics, 106, 37-51. https://doi.org/10.1007/s10551-011-1071-y

Domina, T., \& Koch, K. (1998). Environmental profiles of female apparel shoppers in the Midwest, USA. Journal of Consumer Studies \& Home Economics, 22, 147-117. https://doi.org/10.1111/j.1470-6431.1998.tb00726.x

Eom, H. J., Seock, Y. K., \& Hunt-Hurst, P. (2019). Purchase Intention toward Luxury Brands among Young Adult Consumers from Social Comparison Perspective. Journal of Marketing Management and Consumer Behavior, 2, $1-16$.

Freire, N. A. (2014). When luxury advertising adds the identitary values of luxury: A semiotic analysis. Journal of Business Research, 67, 2666-2675. https://doi.org/10.1016/j.jbusres.2014.04.004

Goworek, H., Fisher, T., Cooper, T., Woodward, S., \& Hiller, A. (2012). The sustainable clothing market: An evaluation 
of potential strategies for UK retailers. International Journal of Retail \& Distribution Management, 40, 935-955. https://doi.org/10.1108/09590551211274937

Han, J., Seo, Y., \& Ko, E. (2017). Staging luxury experiences for understanding sustainable fashion consumption: A balance theory application. Journal of Business Research, 74, 162-167.

https://doi.org/10.1016/j.jbusres.2016.10.029

Husvedt, G., \& Dickson, M. A. (2009). Consumer likelihood of purchasing organic cotton apparel: Influence of attitude and self-identity. Journal of Fashion Marketing and Management, 13, 49-65. https://doi.org/10.1108/13612020910939879

Joergens, C. (2006). Ethical fashion: myth or future trend? Journal of Fashion Marketing and Management, 10, 360-371. https://doi.org/10.1108/13612020610679321

Joy, A., Sherry, J. F., Venkatesh, A. J., Wang, J., \& Chan, R. (2012). Fast fashion,Sustainability, andthe ethical appealof luxury brands. Fashion Theory, 16, 273-296. https://doi.org/10.2752/175174112X13340749707123

Kang, J., Liu, C., \& Kim, S. H. (2013). Environmentally sustainable textile and apparel consumption: the role of consumer knowledge, perceived consumer effectiveness and perceived personal relevance. International Journal of Consumer Studies, 37, 442-452. https://doi.org/10.1111/ijcs.12013

Kapferer, J. N. (2010). All that glitters is not green: The challenge of sustainable luxury. European Business Review, $40-45$.

Kim, S., \& Damhorst, M. L. (1998). Environmental concern and apparel consumption. Clothing and Textiles Research Journal, 16, 126-133. https://doi.org/10.1177/0887302X9801600303

Liberman, N., \& Trope, Y. (1998). The role of feasibility and desirability considerations in near and distant future decisions: A test of temporal construal theory. Journal of Personality and Social Psychology, 75, 5-18. https://doi.org/10.1037/0022-3514.75.1.5

Lindenberg, S., \& Steg, L. (2007). Normative, gain and hedonic goal frames guiding environmental behavior. Journal of Social Issues, 63, 117-137. https://doi.org/10.1111/j.1540-4560.2007.00499.x

Lundblad, L., \& Davies, I. A. (2016). The values and motivations behind sustainable fashion consumption. Journal of Consumer Behavior, 15, 149-162. https://doi.org/10.1002/cb.1559

Markus, H., \& Kitayama, S. (1991). Culture and the self: Implications for cognition, emotion and motivation. Psychological Review, 98, 224-253. https://doi.org/10.1037/0033-295X.98.2.224

Matthes, J., \& Wonneberger, A. (2014). The skeptical green consumer revisited: Testing the relationship between green consumerism and skepticism toward advertising, Journal of Advertising, 43, 115- 127. https://doi.org/10.1080/00913367.2013.834804

Oyserman, D. (2013). Not just any path: implication of identity-based motivation for disparities in school outcomes. Economics of Education Review, 33, 179-190. https://doi.org/10.1016/j.econedurev.2012.09.002

Parguel, B., Benoit-Moreau, F., \& Larceneux, F. (2011). How sustainability ratings might deter 'greenwashing': A closer look at ethical corporate communication. Journal of Business Ethics, 102, 15-28. https://doi.org/10.1007/s10551-011-0901-2

Polonsky, M. J., Grau, S. L., \& Garma, R. (2010). The new greenwash? Potential marketing problems with carbon offsets. International Journal of Business Studies, 18, 49-54.

Ritch, E. L., \& Schröder, M. J. (2012). Accessing and affording sustainability: the experience of fashion consumption within young families. International Journal of Consumer Studies, 36, 203-210. https://doi.org/10.1111/j.1470-6431.2011.01088.x

Roberts, J. A. (1996). Green consumers in the 1990s: profile and implications for advertising. Journal of Business Research, 36, 217-231. https://doi.org/10.1016/0148-2963(95)00150-6

Sheehan, K., \& Atkinson, L. (2012). Special Issue on green advertising: Revisiting green advertising and the reluctant consumer. Journal of Advertising, 41, 5-7. https://doi.org/10.1080/00913367.2012.10672453

Shen, B., Wang, Y., Lo, C. K., \& Shum, M. (2012). The impact of ethical fashion on consumer purchase behavior. Journal of Fashion Marketing and Management: An International Journal, 16, 234-245. https://doi.org/10.1108/13612021211222842

Singelis, T. (1994). The measurement of independent and interdependent self-construals. Personality and Social Psychology Bulletin, 20, 580-591. https://doi.org/10.1177/0146167294205014 
Soh, H., Reid, L. N., \& King, K. W. (2009). Measuring trust in advertising. Journal of Advertising, 38, 83-104. https://doi.org/10.2753/JOA0091-3367380206

Steinhart, Y., Ayalon, O., \& Puterman, H. (2013). The effect of an environmental claim on consumers' perceptions about luxury and utilitarian products. Journal of Cleaner Production, 53, 277-286. https://doi.org/10.1016/j.jclepro.2013.04.024

Szmigin, I., Carrigan, M., \& McEachern, M. G. (2009). The conscious consumer. Taking a flexible approach to ethical behavior. International Journal of Consumer Studies, 33, 224-231. https://doi.org/10.1111/j.1470-6431.2009.00750.x

Todeschini, B. V., Cortimiglia, M. N., Callegaro-de-Menezes, D., \& Ghezzi, A. (2017). Innovative and sustainable business models in the fashion industry: Entrepreneurial drivers, opportunities, and challenges. Business Horizons, 60, 759-770. https://doi.org/10.1016/j.bushor.2017.07.003

Trope, Y., \& Liberman, N. (2010). Construal-level theory of psychological distance. Psychological Review, 117, 440-463. https://doi.org/10.1037/a0018963

Trope, Y., Liberman, N., \& Wakslak, C. (2007). Construal levels and psychological distance: Effects on representation, prediction, evaluation, and behavior. Journal of Consumer Psychology, 17, 83-95. https://doi.org/10.1016/S1057-7408(07)70013-X

Vermeir, I., \& Verbeke, W. (2006). Sustainable food consumption: exploring the consumer 'attitude - behavioral intention' gap. Journal of Agriculture and Environmental Ethics, 19, 169-194. https://doi.org/10.1007/s10806-005-5485-3

Webb, D. J., Mohr, L. A., \& Kim, E. Y. (2012). The role of perceived consumer effectiveness and motivational attitude on socially responsible purchasing behavior in South Korea. Journal of Global Marketing, 25, 29-44. https://doi.org/10.1080/08911762.2012.697383

White, K., \& Simpson, B. (2013). When do (and don't) normative appeals influence sustainable consumer behaviors? Journal of Marketing, 77, 78-95. https://doi.org/10.1509/jm.11.0278

Zaickowsky, J. L. (1985). Measuring the involvement construct. Journal of Consumer Research, 12, 341-352. https://doi.org/10.1086/208520

\section{Copyrights}

Copyright for this article is retained by the author(s), with first publication rights granted to the journal.

This is an open-access article distributed under the terms and conditions of the Creative Commons Attribution license which permits unrestricted use, distribution, and reproduction in any medium, provided the original work is properly cited. 